\title{
IMPLICAÇÕES DOCENTES E DISCENTES NA UTILIZAÇÃO DAS NOVAS TIC NO PROCESSO DE ENSINO-APRENDIZAGEM DE LÍNGUA INGLESA ${ }^{1}$
TEACHER AND STUDENT IMPLICATIONS IN THE USE OF THE NEW ICT IN THE ENGLISH LANGUAGE LEARNING-TEACHING PROCESS

\author{
Luiz Henrique Mendes Brandão \\ Universidade Estadual de Minas Gerais \\ luizwhitemetal@yahoo.com.br \\ Jesiel Soares Silva \\ Universidade Estadual de Minas Gerais \\ jesielsoaressilva@gmail.com
}

\begin{abstract}
RESUMO: Neste trabalho, objetivamos analisar as implicações docentes e discentes no processo de ensino-aprendizagem de língua inglesa. Para tal, avaliamos a utilização, por parte dos professores dessa língua, de materiais em vídeo, músicas, entre outras mídias advindas dessas novas TIC, tanto em escolas públicas quanto particulares, considerando a percepção dos professores e alunos. Como procedimento de investigação, aplicamos um questionário a professores e alunos de seis escolas da região do Barreiro, em Belo Horizonte - MG (Brasil). Com base nas respostas obtidas, verificamos um baixo índice de aproveitamento das potencialidades das novas TIC, em especial nas escolas públicas, mas também nas escolas particulares.
\end{abstract}

PALAVRAS-CHAVE: novas TIC; ensino-aprendizagem de língua inglesa; materiais autênticos.

ABSTRACT: In this paper we aimed at analyzing the implications concerning teachers and students in the English teaching-learning process. To do so, we assessed the English teachers' use of video materials, music, among other media provided by the new ICT, both in public and private schools, relying on teachers' and students' perceptions. As investigation procedure, we applied a multiple-item questionnaire to teachers and students from six schools in the neighborhood of Barreiro, in Belo Horizonte - Minas Gerais (Brazil). Through the answers, we verified a low rate of exploration of the potentialities provided by the new ICT, especially in public schools, but also in the private ones.

KEYWORDS: new ICT; English language teaching-learning; authentic materials.

\section{Introdução}

Ao longo dos últimos anos, o ser humano tem se servido de diversos recursos e possibilidades tecnológicas que o tem permitido ampliar e facilitar sua experiência comunicativa e informativa. Ferramentas como computadores, tablets e celulares, bem

1 Este artigo é fruto de um Trabalho de Conclusão de Curso que foi desenvolvido na UEMG Ibirité em 2017. 
como outras do grupo das novas Tecnologias da Informação e Comunicação (TIC) têm se mostrado aliadas fiéis nesse processo nos últimos anos.

Para docentes e discentes, a importância de se estudar as novas TIC no escopo do processo de ensino-aprendizagem da língua inglesa (LI) remete a uma conscientização sobre ferramentas que têm potencial de tornar a aquisição da língua mais relevante, fácil e culturalmente rica. Segundo Koksal (2004, p. 62), as novas TIC se desenvolvem e são disseminadas tão rapidamente que sua atração e influência não podem ser evitadas. Segundo argumenta Watson (2001, p. 252), as escolas não devem munir os alunos com tecnologias e habilidades ultrapassadas, sob pena de produzir pessoas desconectadas com o mundo de amanhã. Considerando que o uso dessas ferramentas pode vir a interferir no ensino e aprendizagem de língua, buscamos entender quais são as consequências de sua utilização nesse processo.

No intuito de abordarmos esse problema de pesquisa de forma investigativa e qualitativa, propomos alguns objetivos que nortearam os caminhos deste empreendimento científico. Sendo assim, o objetivo geral foi o de identificar quais são as implicações docentes e discentes na utilização das novas TIC no processo de ensino-aprendizagem de LI. Além disso, como objetivos específicos, buscamos aferir e entender as práticas e percepções docentes e discentes em relação à utilização das novas TIC em sala de aula no que se refere a possibilidades advindas com elas como a utilização de vídeos e músicas nesse ambiente; bem como intencionamos entender a realidade de escolas públicas e particulares e lançar um olhar mais aprofundado para o aluno de LI em si.

Para conduzirmos os procedimentos de pesquisa e alcançarmos os objetivos acima elencados, propomos duas perguntas de pesquisa, a saber: I) como se dá a utilização das novas TIC no processo de ensino-aprendizagem de LI e de que maneira professores e alunos se inserem nesse cenário? II) segundo os relatos de professores e alunos ${ }^{2}$, como as novas TIC são utilizadas para o acesso a materiais audiovisuais autênticos com ou sem legendas, em ambiente de aprendizagem formal e informal, dentro de escolas públicas e privadas da cidade de Belo Horizonte-MG?

Tendo explicitado os pontos acima, informamos que este artigo está composto de cinco partes. A primeira é a introdução, onde o problema de pesquisa e, consequentemente, os objetivos, são apresentados. A segunda compreende o referencial teórico, em que as principais teorias e seus respectivos autores que fundamentam o objetivo da pesquisa são abordados. A terceira versa sobre a metodologia da pesquisa, na qual o tipo de pesquisa, os métodos e as técnicas utilizados na investigação são introduzidos. A quarta seção se debruça sobre a análise de dados, onde a teoria é comparada com os dados encontrados na pesquisa de campo. Por fim, a última parte apresenta as considerações finais, em que os resultados encontrados e que respondem ao problema de pesquisa são comentados, bem como as limitações da pesquisa são listadas.

2 Todos os indivíduos que responderam aos questionários utilizados nesta pesquisa, bem como as instituições em que lecionam/estudam, foram informados oralmente e por escrito sobre a sua natureza, consentindo voluntariamente em participar dela. Tais pessoas e instituições foram cientificadas de todas as medidas éticas empregadas no manuseio das informações colhidas por meio dos questionários. 


\section{Referencial teórico}

Abordar um tema tão complexo como o uso das novas TIC no ensinoaprendizagem de LI requer certo critério ao selecionar estudos que estejam alinhados com as mais recentes atualizações concernentes ao tema, que está em constante evolução, e que apresentem resultados e problemas relevantes e atuais. Ao considerarmos tal cenário, dividiremos nosso referencial teórico nos seguintes subtópicos: teorias sobre o processo de ensino-aprendizagem; Computer assisted language learning (CALL), que significa aprendizagem de línguas mediada por computador; e um breve panorama sobre o papel das TIC no processo de ensino-aprendizagem de LI.

\subsection{A hipótese do input (Input Hypothesis) na teoria de Krashen acerca da aquisição de segunda língua (L2)}

A hipótese do input (input hypothesis) é um dos pontos centrais na teoria de Krashen, que postula ser o papel do professor fazer pelo aluno o que o mundo lá fora não pode ou não irá fazer, ou seja, tornar o conteúdo linguístico que ele recebe (input) mais compreensível.

Krashen (2009, p. 10) apresenta uma distinção conceitual sobre aquisição e aprendizagem de segunda língua (L2). Para ele, aquisição é o processo subconsciente pelo qual alguém assimila a língua de forma natural, informal e implícita, enquanto que aprendizagem refere-se ao conhecimento consciente de uma língua, ou seja, suas regras, bem como ao estado se estar consciente e saber falar a respeito delas. $O$ autor propõe ainda que a condição necessária (mas não suficiente) para que o aprendiz ascenda de nível é que ele entenda o conteúdo ministrado a ele, e este entender significa estar focado no significado e não na forma da mensagem. O conteúdo ao qual somos expostos deve estar apenas um pouco além do nível em que já nos encontramos e ser compreensível a nós para que a aquisição seja bem-sucedida. Outro ponto da hipótese é o de que a habilidade de fala não pode ser ensinada diretamente, pois ela emerge sozinha com o tempo através de constante exposição à língua.

\subsection{Hipótese do filtro afetivo (affective filter hypothesis)}

A hipótese do filtro afetivo (affective filter hypothesis) propõe que uma série de variáveis afetivas estão relacionadas ao sucesso na aquisição de L2. Tal hipótese foi inicialmente proposta por Dulay e Burt (1977 apud KRASHEN, 2009, p. 30-31) ${ }^{3}$ e confirmada por estudos diversos após sua introdução. Os diversos fatores afetivos que facilitam a aquisição podem ser, em sua maioria, colocados em uma das três categorias seguintes: motivação, autoconfiança e baixa ansiedade (KRASHEN, 2009, p. 31). Quanto maior for o nível desses fatores, mais baixo será o filtro afetivo e, portanto, melhor a aquisição da língua.

3 DULAY, H.; BURT, M. Remarks on creativity in language acquisition. In: BURT, M.; DULAY, H; FINNOCHIARO, M. (Eds.). Viewpoints on English as a Second Language. 1. ed. New York: Regents, 1977. p. 95-126. 
A formulação de Krashen (2009, p. 30-32) assevera que aqueles desprovidos de uma atitude ideal na aquisição de L2 não só buscarão menos conteúdo na língua-alvo como também terão um filtro afetivo alto, o que fará com que, mesmo entendendo a mensagem, eles terão certa dificuldade, pois o conteúdo não alcançará a parte do cérebro responsável pela aquisição de linguagem. Além disso, a hipótese do input e o conceito de filtro afetivo definem o professor de línguas de uma nova forma, segundo Krashen (2009, p. 32): "o professor eficiente de línguas é alguém que consegue prover conteúdo e ajudar a fazê-lo compreensível em uma situação de baixa ansiedade".

O ambiente escolar, conforme idealizado por Krashen (2009), pode diminuir o filtro afetivo dos estudantes se houver uma sala de aula agradável e com iluminação adequada, se os professores tiverem uma personalidade dinâmica e pensarem as aulas como uma atuação teatral, se corrigirem os erros dos discentes de forma adequada e se houver um nível adequado de aculturação envolvido. Esses são fatores tidos como positivos e são cruciais para a diminuição do filtro afetivo e a criação de um ambiente adequado para que a aquisição de linguagem ocorra.

Para se tornar esse tipo de profissional apontado por Krashen (2009, p. 32), é desejável que os docentes adquiram habilidades para o aproveitamento de todo tipo de recurso disponível que possa auxiliá-los nessa busca. No presente momento, temos valiosas ferramentas educacionais à nossa disposição, surgidas com o advento dos computadores e o que emergiu a partir daí. Desse modo, faz-se relevante que aquele que ensina se inteire sobre a CALL.

\subsection{CALL (Computer Assisted Language Learning)}

A Aprendizagem de idiomas mediada pelo computador (ou CALL, da sigla em inglês) é uma prática que, segundo Warschauer e Healey (1998, p. 1), foi concebida na década de 1950 e implementada nas duas décadas posteriores.

O primeiro estágio da CALL, denominado behaviorista, foi baseado em uma concepção comportamental da relação homem-máquina. Este foi um estágio em que os computadores auxiliavam na aprendizagem de línguas através de exercícios focados na repetição de estruturas gramaticais (conhecidos como drills). Nesse paradigma, o computador era visto como um tutor que nunca se cansava de emitir feedback para os aprendizes. Warschauer e Healey (1998, p. 1) citam o PLATO, que foi o mais conhecido sistema tutorial dessa fase da CALL. O sistema era executado em hardware próprio e realizava testes de tradução, explicações gramaticais e extensivos drills.

No final dos anos 1970, emergiu um novo estágio da CALL, chamado CALL comunicativo. Segundo Warschauer e Healey $(1998$, p. 1), isso ocorreu ao mesmo tempo em que o behaviorismo começava a ser rejeitado, tanto no campo teórico quanto no pedagógico, e quando novos computadores estavam criando maiores possibilidades de trabalho individual. Os proponentes deste segundo estágio da CALL realçaram que o foco das atividades com computador deveria ser não em aprender sobre as estruturas da língua, mas a usá-las de forma contextualizada.

Neste período, como afirmam Warschauer e Healey (1998, p. 1), eram populares programas de reconstrução textual que permitiam aos alunos, quer individualmente quer em grupos, rearranjar palavras em textos e descobrir padrões de linguagem e significado, 
através de programas de simulação, que simulavam discussões e descobertas entre alunos trabalhando em pares ou grupos.

No fim dos anos 1980 e início dos anos 1990, houve a migração de muitos professores do ensino comunicativo para uma abordagem mais sociocognitiva, com ênfase no uso da língua em contextos sociais reais e com abordagens que levassem os alunos a interagirem em ambientes autênticos. Nesse bojo, surge o conceito de CALL integrativo. Esse estágio busca integrar melhor as habilidades linguísticas dos alunos, bem como fornecer assistência da tecnologia ao processo de aprendizagem.

Segundo Warschauer (1996, p. 4), as abordagens integrativas da CALL se basearam em dois importantes avanços tecnológicos: os computadores multimídia e a internet. $\mathrm{Na}$ mesma linha de pensamento, Silva (2011, p. 51) lembra que, com o surgimento da internet e a hipermídia, mecanismo propiciador de leituras textuais não lineares auxiliadas por recursos como imagens, sons, entre outros, a CALL integrativa trouxe a novidade da integração de texto oral e escrito. A imagem e o som se tornam integrados em partes de um mesmo todo, aumentando a possibilidade de significação e ressignificação do texto pelo aprendiz. Silva (2011, p. 52) cita o papel-chave da internet neste estágio da CALL, isto é, integrar pessoas e comunidades separadas geograficamente ao retomar conceitos do sociointeracionismo. Um fator central para a ocorrência de tal fato foi o surgimento da Web 2.0, como será visto no subtópico a seguir.

\subsubsection{Web 2.0}

O termo Web 2.0 se refere, conforme definição de Mcloughlin e Lee (2007), à segunda geração de serviços on-line, sendo esta caracterizada por sua inovação na forma de publicação, compartilhamento e organização de informações. O conceito permite maior interação entre os usuários da internet à medida que os transforma de meros espectadores em participantes ativos no processo de construção de conteúdo e informação no meio virtual.

A internet era anteriormente uma via praticamente de mão única, devido à falta, entre outros fatores, de conhecimento técnico dos usuários para participar mais ativamente na construção de conteúdos. Com a internet 2.0, todos passaram a ter acesso fácil sem a necessidade de conhecimentos de programação.

Com o advento da Web 2.0, o acesso à internet já não está mais limitado a computadores. Temos hoje diversos tipos de dispositivos que se conectam à rede mundial, entre eles os celulares. Essa realidade deu origem a novas formas de pensar a CALL, como veremos na subseção seguinte.

\subsubsection{Da CALL ao MALU}

Concordamos com Jarvie e Achilleos (2013, p. 2) sobre o fato de que o acrônimo CALL já não se adéqua, há algum tempo, ao seu propósito, pois com a democratização da internet e a multiplicação dos meios das novas tecnologias, os computadores já não são os únicos do gênero a propiciar tal experiência de aprendizagem. Celulares e diversos outros aparelhos móveis têm sido desenvolvidos com incrível rapidez nos últimos anos. 
O aumento da disponibilidade de aparelhos móveis como celulares, leitores de ebooks (livros digitais), entre outros, levou-nos ao conceito de aprendizagem de línguas mediada por tais dispositivos móveis. Nasce assim o conceito de aprendizagem de línguas mediada por aparelhos móveis, ou no termo em inglês, Mobile Assisted Language Learning (MALL), que, segundo Hulme e Shield (2008, p. 3), difere-se do conceito de CALL por utilizar aparelhos móveis que possibilitam novas formas de aprendizagem, enfatizando a continuidade e espontaneidade do acesso por diferentes contextos de uso.

No que aqui nos interessa, um número elevado de publicações têm sido feitas sobre esse tema, principalmente nos últimos anos, dentre as quais citamos as pesquisas de Lindaman e Nolan (2015) e Hulme e Shield (2008). Uma das propostas de utilização notável propiciadas pela MALL é a criação de aplicativos pedagógicos por parte de professores e gestores educacionais. Nesse sentido, Lindaman e Nolan (2015, p. 10-17) nos apresentam alguns projetos desses aplicativos de aprendizagem de línguas e seus resultados.

No entanto, não é apenas com celulares que a prática educativa através da MALL se materializa. Hulme e Shield (2008, p. 4-8) elencam vários tipos de dispositivos que estavam em voga em 2008, como computadores de mão, tocadores de mp3 e gravadores de áudio, bem como seus usos aplicados ao ensino-aprendizagem de línguas.

A MALL, segundo Jarvie e Achilleos (2013, p. 3), também apresenta uma limitação em si, pois se concentra no uso compartilhado com a CALL do conceito de aprendizagem de idiomas. Sendo assim, faz-se necessária uma definição que reconheça os usos sociais na L2 em situações de aprendizagem formais e menos formais. Sendo assim, os autores introduzem um novo conceito, isto é, o uso da língua mediado por dispositivos móveis, conhecido como Mobile Assisted Language Use (MALU), que, segundo os pesquisadores, consegue compreender toda a gama de possibilidades advindas tanto da CALL quanto da MALL. Os autores admitem que o termo CALL continua relevante, pois, de acordo com a pesquisa feita por eles, o computador ainda é o meio preferido pelos estudantes quando se trata de atividades de aprendizagem consciente, mas argumentam que há uma demanda por uma visão mais abrangente, o que é proposto com o acrônimo MALU, que é definido pelos autores da seguinte forma:

Falantes não-nativos fazendo uso de uma variedade de dispositivos móveis com o objetivo de acessar e/ou comunicar informação a qualquer hora e em qualquer lugar e para uma gama de propósitos sociais e/ou acadêmicos em uma segunda língua. [...] [O termo] reconhece também que os dispositivos podem ser usados não apenas como um meio para um fim, onde o fim é a aprendizagem de idiomas, mas também onde o fim é acessar e postar informações como cidadãos globalmente conectados com o inglês (inglês como segunda língua), assim como utilizando a língua mãe como estratégia para tal (JARVIE; ACHILLEOS, 2013, p. $9)^{45}$.

4 Traduzido de: "Non-native speakers using of a variety of mobile devices in order to access and/or communicate information on an anywhere/anytime basis and for a range of social and/or academic purposes in L2. [...] It recognises that devices can be used not only as a means to an end, where the end is language learning, but also where the end is accessing and posting information as globally networked citizens with English (as the L2) as well as L1 being the means to do so." (JARVIE; ACHILLEOS, 2013, p. 9).

5 Todas as traduções neste trabalho são de responsabilidade dos autores. 
Em conclusão, Jarvie e Achilleos (2013, p. 10) sugerem que a mudança para o MALU tem o potencial de complementar uma recém emergente teoria do conectivismo (connectivism) mais que a CALL já foi capaz de fazer. Concordamos com Jarvie e Achilleos (2013, p. 10) que a proposta do MALU é mais condizente com as teorias de aprendizagem emergentes.

As propostas de aprendizagem citadas nesta subseção estão intimamente vinculadas às TIC, tema este sobre o qual falaremos na subseção seguinte.

\subsection{Um breve panorama sobre o papel das TIC no processo de ensino- aprendizagem de LI}

Seja como ferramentas de interação, seja como instrumentos de comunicação ou até por vezes como facilitadoras dos processos de aprendizagem, as TIC estão presentes no cotidiano das pessoas de forma substantiva atualmente. Computadores, celulares e tablets tornaram-se necessários no contexto social em que nos encontramos.

As TIC são definidas por Ghasemi e Hashemi (2011, p. 3098) como "um conjunto diverso de ferramentas e recursos tecnológicos usados para criar, disseminar, armazenar e gerenciar informação"6. Os autores citam como exemplos dessas ferramentas computadores, internet, tecnologias de radiodifusão (rádio e televisão) e telefonia.

Os pesquisadores também discorrem sobre o uso das novas TIC no processo de ensino-aprendizagem de línguas. Para eles, essas tecnologias proporcionam aos aprendizes exposição real à cultura dos povos e países onde a língua-alvo é falada; facilitam a comunicação e interação com falantes nativos e outras comunidades, o que possibilita a utilização da língua para propósitos reais em contextos reais; fortalecem e integram as habilidades literárias; realçam estilos interativos de aprendizagem e ensino e promovem e oportunizam a criatividade, o que os autores assinalam como fator de motivação altamente contributivo no processo de aprendizagem.

Na mesma linha de pensamento, Richards (2001, p. 252) assevera que a utilização de material autêntico é um fator importante no processo de ensino-aprendizagem de uma língua. O material autêntico é aquele que não é concebido com propósitos pedagógicos, mas foi feito para nativos, tais como jornais, revistas, vídeos e outros recursos pedagógicos. O autor destaca ainda os benefícios possíveis da utilização desse tipo de material em sala de aula, tais como o efeito positivo na motivação do aprendiz, a disponibilização de informação cultural autêntica e de exposição à linguagem real em um contexto real de comunicação, o melhor atendimento às necessidades dos aprendizes e o favorecimento a uma técnica educativa mais criativa.

\subsubsection{Novas TIC e a legendagem}

O estudo de Neuman e Koskinen (1992, p. 101-105) demonstrou, através da exposição de estudantes bilíngues a vídeos com e sem legendas, que a legendagem é uma forma útil de se transformar materiais autênticos em materiais compreensíveis e que,

6 Traduzido de: "[...] a diverse set of technological tools and resources used to communicate, and to create, disseminate, store, and manage information" (GHASEMI; HASHEMI, 2011, p. 3098). 
desta forma, há maior retenção de palavras.

Outro estudo sobre legendagem é o de Huang e Eskey (1999, p. 86). Ao pesquisarem os efeitos da utilização de legendas na compreensão oral de alunos de inglês como segunda língua (ESL), os pesquisadores descobriram que esse recurso ajudou os participantes na aquisição de vocabulário e na compreensão oral e leitora.

Resultados igualmente positivos foram observados em pesquisa feita por Vanderplank (1988, p. 276), que mostrou que a utilização de legendas, em vez de ser uma distração, pode trazer benefícios aos que têm dificuldades com a compreensão oral.

Além disso, estudos como os de Markham, Peter e Mccarthy (2001, p. 443-444) e Markham e Peter (2003, p. 337-340) asseveraram que alunos que são expostos a legendas interlinguísticas (aquelas produzidas na língua mãe dos espectadores e não na sua língua-alvo) obtêm uma melhor compreensão do conteúdo dos materiais do que os que são expostos ao mesmo material com legendas intralinguísticas (feitas na línguaalvo).

Outro recurso que se têm apontado e utilizado no processo de ensinoaprendizagem de LI é a música. No entanto, é necessário que se entenda como se beneficiar dele, como será visto a seguir

\subsubsection{As novas TIC e a música}

Mais que uma simples forma de divertimento ou relaxamento, a música, ao longo da história da humanidade, tem servido como meio de comunicação dos mais diversos ideais e com diferentes fins, sejam educativos, políticos, religiosos, entre ou tros. Merriam (1964) discorre sobre a importância da música nas mais diversas civilizações humanas, seu papel na manutenção da literatura de um povo, seus valores religiosos, culturais, políticos. O autor fala ainda sobre a influência que ela exerce sobre aspectos psicológicos e até mesmo fisiológicos do ser humano.

Para exemplificar, Yousefi, Yekta e Farahmandian (2014, p. 2585-2586) descobriram que pessoas expostas a conteúdo musical retêm mais vocábulos do que os submetidos ao mesmo conteúdo de forma não musical. Outros três autores que discutem a importância do componente musical em processos de aprendizagem são Israel (2013), Engh (2013) e Lems (2016). Entre eles, Engh (2013, p. 113), aponta a falta de conhecimento teórico por parte do professor sobre como utilizar música em suas aulas como responsável pela pouca exploração deste recurso que pode potencializar a aprendizagem.

As novas TIC não devem ser utilizadas de forma desvinculada de boas práticas pedagógicas dentro do ambiente escolar. Os professores são responsáveis pela compreensão e apropriação dos benefícios criados pelas TIC dentro de uma prática docente adequada.

\subsubsection{Novas TIC e as atribuições docentes}

Como alertam Ghasemi e Hashemi (2011, p. 3100-3101), as novas TIC por si só são apenas instrumentos, e é então necessário que os professores estejam alinhados com modernas práticas pedagógicas. Segundo Hashemi (2013, p. 65), há três fatores que 
influenciam na utilização ou não de tecnologias por professores em sala de aula, a saber: fatores pessoais, institucionais e tecnológicos. Entre eles, este último se refere, por exemplo, à falta de preparo dos profissionais para a correta utilização das novas TIC em suas aulas.

Segundo Hashemi (2013, p. 58-59), a realidade de utilização das novas TIC na vida do docente e sua atitude para com esses recursos influencia em sua utilização ou não em sala de aula.

Seguindo o mesmo caminho, Silva e Medeiros (2014, p. 2) afirmam que as tecnologias não mudam necessariamente a relação pedagógica, pois são ferramentas que podem ser utilizadas tanto para perpetuar uma didática ultrapassada e ineficaz, quanto para se apoiar uma prática moderna, interativa e participativa. Sendo assim, há que se transformar a própria prática educativa.

Os autores apontaram que as escolas estão recebendo laboratórios de informática por incentivo de programas como o PROINFO (Programa nacional de informática na educação), mas que o uso desses espaços tem sido obsoleto. Os professores receberam curso de capacitação para a utilização do espaço, mas, segundo os próprios docentes, motivos como a falta de tempo disponível para o planejamento de aulas diversificadas, significativo domínio da ferramenta e falta de condições organizacionais são alguns dos fatores responsáveis pela pouca utilização do laboratório. Resultados semelhantes a esses foram verificados por Carvalho (2012, p. 49-51), que também constatou ineficiência ao investigar em Londrina/PR o uso de tecnologias na educação pública, em especial o dos laboratórios de informática.

\subsubsection{Gestão educacional e as novas TIC: Teoria e prática observada em escolas públicas e particulares}

No ano de 1990, foi realizada em Jomtien, na Tailândia, a conferência mundial sobre educação para todos, com o objetivo de satisfazer as necessidades básicas de todas as crianças, jovens e adultos. Um documento denominado Declaração de Jomtien ${ }^{7}$ foi produzido na ocasião da conferência, certificando os compromissos firmados pelos países participantes. No texto da declaração, as TIC foram apontadas como fatores que melhoram a qualidade e oferta da educação básica, bem como sua gestão.

O Brasil foi um dos 150 países que assinaram o documento se comprometendo a implementar e ampliar o uso de tais recursos na educação. Uma das medidas tomadas em direção a implementação das TIC na educação básica brasileira foi a criação do Programa Nacional de Tecnologia Educacional (PROINFO) em 1997, que é uma iniciativa que visa promover o uso pedagógico das TIC na rede pública de educação básica. $O$ Ministério da Educação e Cultura (MEC), através do programa, compra, distribui e instala laboratórios de informática nas escolas públicas de ensino básico. As escolas selecionadas devem providenciar a infraestrutura necessária. O PROINFO ${ }^{8}$ foi remodelado em 2007 e passou a se chamar Programa Nacional de Tecnologia Educacional, mantendo, porém, a mesma sigla de origem e as práticas aqui

7 UNESCO, 1990.

8 (BRASIL, 2007). 
mencionadas.

Outro programa mais recente voltado ao uso da tecnologia na rede pública é o Programa Um Computador por Aluno (PROUCA). O PROUCA foi instituído em 2010 e facilita a compra de computadores para estados, municípios e Distrito Federal, que queiram adquirir computadores para suas escolas com recursos próprios ou através de empréstimo do Banco Nacional de Desenvolvimento Econômico e Social (BNDES), o programa também prevê treinamento aos docentes para utilização dos recursos.

Entretanto, estudos relativamente recentes como os de Silva (2014, p. 121; 185192) apontam para uma precariedade dos equipamentos e infraestrutura desde o início do PROINFO até o início da aplicação do PROUCA, bem como o déficit na capacitação dos professores para a utilização desses recursos (Silva, 2014, p. 269-273). Damasceno, Bonilla e Passos (2012, p. 33) questionam a eficácia do PROINFO, mostram dados que demonstram a preferência da população ao acesso público pago à internet (em lan houses, por exemplo) em vez do gratuito público. Silva (2014, p. 121), por sua vez, afirma que grande parte do que foi anunciado para o programa PROINFO não se cumpriu.

Barros e Araújo (2012, p. 5-9) reafirmam a precariedade das estruturas em escolas públicas, bem como a falta de qualificação dos profissionais, que acabam se voltando para uma forma de ensino que deixa de contribuir como poderia, por exemplo, para o processo de promoção da autonomia dos estudantes, processo este que encontra na utilização das novas TIC uma importante aliada. Os autores fazem um paralelo com as instituições particulares, que, além de terem excelentes estruturas físicas, com ambientes climatizados amplos, bem iluminados e aparatos tecnológicos modernos, ainda possuem profissionais bem qualificados e com formação específica para o melhor proveito dos recursos oferecidos.

Tanto escolas públicas quanto particulares contam com o auxílio que foi criado para servir como referência para o ensino básico no Brasil, que são os Parâmetros Curriculares Nacionais (PCNs). Estes documentos são referência para o Ensino Fundamental e Médio de todo o país e não devem ser tomados como regras, mas como propostas que podem ser adaptadas às peculiaridades locais. Os PCNs colocam como objetivo dos envolvidos na prática escolar "entender os princípios das tecnologias da comunicação e da informação, associá-las aos conhecimentos científicos, às linguagens que lhes dão suporte e aos problemas que se propõem a solucionar." (BRASIL, 2000, p. 11). As novas TIC são abordadas no documento como ferramentas que permeiam o cotidiano, independente do espaço físico, criando necessidades de vida e convivência que precisam ser analisadas no espaço escolar. Além dos PCNs, a Base Nacional Comum Curricular (BNCC) estabelece como competência geral da educação básica que o sujeito deve:

Compreender, utilizar e criar tecnologias digitais de informação e comunicação de forma crítica, significativa, reflexiva e ética nas diversas práticas sociais (incluindo as escolares) para se comunicar, acessar e disseminar informações, produzir conhecimentos, resolver problemas e exercer protagonismo e autoria na vida pessoal e coletiva (BRASIL, 2017, p. 9).

Ao considerarmos todas as nuances dispostas no cenário das novas TIC, obtivemos uma percepção mais holística sobre a extensão das possibilidades oferecidas por tais recursos, bem como desafios trazidos à existência por esses auxílios. Nesse 
sentido, dispusemo-nos a contribuir com a discussão investigando as implicações docentes e discentes no processo de ensino/aprendizagem de língua inglesa e, para tal, utilizamos procedimentos e técnicas de pesquisa que serão detalhados a seguir.

\section{Metodologia}

Esta pesquisa se caracteriza como uma pesquisa quanti-qualitativa ou híbrida, que é definida por Grim, Harmon e Gromis (2006, p. 2) como: "a incorporação estratégica de técnicas quantitativas dentro de um método qualitativo de forma a fazer com que os resultados sejam mais empiricamente transparentes"9. Tal metodologia, portanto, alicerçase tanto nas bases quantitativas na pesquisa de cunho estatístico, quanto na hermenêutica da pesquisa qualitativa. Os dados qualitativos são fundamentais quando se trata da complexidade humana, uma vez que é possível abordar nuances dos dados que não são quantificáveis, enquanto que os quantitativos trazem maior confiabilidade. Consequentemente, o método que elegemos para este trabalho é a pesquisa de campo, que é definida por Prodanov e Freitas (2013, p. 59) como aquela que consiste na observação de fatos e fenômenos tais como ocorrem espontaneamente, na coleta de dados a eles referentes e no registro de variáveis que presumimos relevantes.

Utilizamos esse método porque intentamos investigar mais profundamente a realidade da educação no que diz respeito à utilização das novas TIC na atualidade diretamente de um contexto real em que ocorrem. Apresentamos, na subseção seguinte, dados detalhados sobre a pesquisa em si.

\subsection{Materiais, procedimentos e participantes}

O instrumento de pesquisa utilizado nesta investigação foi o questionário: um modelo para professores e outro para alunos, contendo cada um três partes, das quais as duas primeiras são quantitativas e a última qualitativa. O dos alunos contém 41 perguntas ao todo e o dos professores 38. Em ambos os questionários, as perguntas são de múltipla escolha em sua maioria, sendo as demais de cunho aberto. Mais especificamente, as perguntas de múltipla escolha foram feitas segundo a escala Likert, que distribui os elementos de forma balanceada para escolha dos participantes. Medimos a partir das respostas a este tipo de questionário a média das respostas, bem como o desvio padrão da amostra, que apresenta o índice de dispersão em torno da média observada. A escala Likert foi adotada por representar uma forma balanceada e prática de aferição.

Os questionários foram aplicados em seis escolas, quatro delas públicas e duas particulares, todas situadas na região do Barreiro, na cidade de Belo Horizonte/MG. O critério de seleção das escolas participantes foi pela localização (próximo à casa dos pesquisadores) e o menor número de escolas particulares em relação às públicas se deve a recusas de participação por parte de duas particulares, dentre as quatro consultadas. A realização das coletas se deu entre os dias 18 de setembro e 20 de outubro de 2017.

Ao todo, 158 indivíduos participaram da pesquisa respondendo aos questionários,

9 Traduzido de: "[...] the strategic incorporation of quantitative techniques into a qualitative method in such a way as to make the results more empirically transparent." (GRIM; HARMON; GROMIS, 2006, p. 2). 
sendo 150 alunos (58 homens e 92 mulheres), com idade de 15 a 20 anos (exceto duas pessoas), 25 de cada escola, além de oito professores (um homem e sete mulheres), todos, com exceção de dois, com mais de 40 anos. Em cada escola ao menos um docente foi consultado. A pesquisa foi feita apenas com alunos e professores do nível médio para fins de uniformização e consequente facilitação do processo de análise dos dados. Prosseguiremos agora com a análise dos dados dos questionários e a observação de fatores convergentes e divergentes na percepção de alunos e professores sobre o uso das novas TIC.

\section{Análise de dados}

Passaremos agora a analisar os resultados encontrados através do questionário da pesquisa de campo que fizemos em seis escolas da região do Barreiro, em Belo Horizonte/MG. Avaliaremos aqui como tem-se dado a utilização das novas TIC pelos professores de LI nessas escolas.

Os primeiros resultados podem ser observados na Figura 1, que apresenta um resumo das respostas dos alunos de escolas públicas e particulares sobre a utilização das novas TIC nesses locais e tratará das diferenças entre escolas em ambas as realidades.

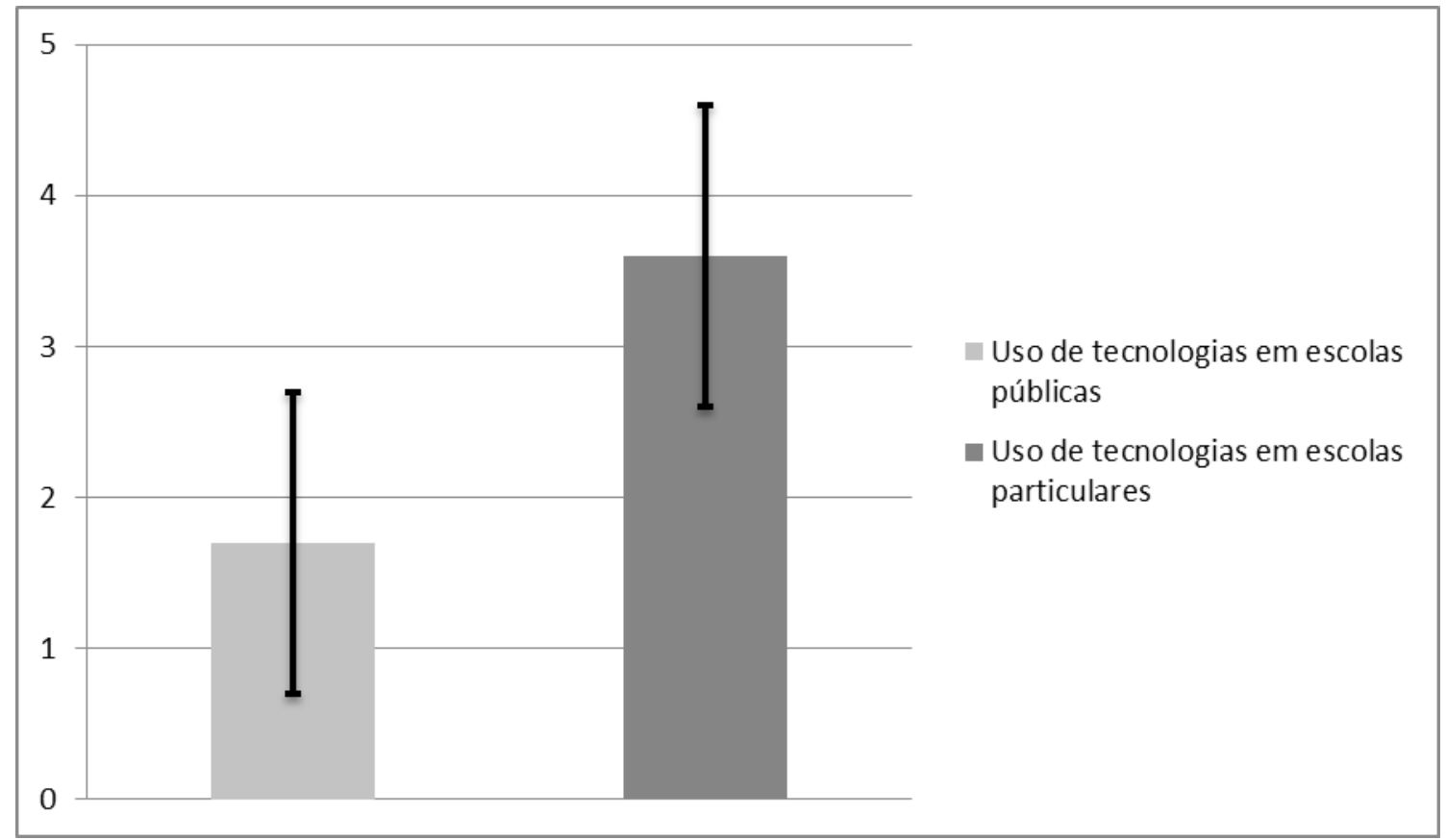

Figura 1: Uso de tecnologias em escolas públicas e particulares.

Fonte: os autores.

A primeira coluna, destacada em cinza mais claro, representa as respostas dos alunos acerca de questões relacionadas à utilização de tecnologias dentro de sala de aula pelos professores. Observamos que seu uso em escolas públicas, de acordo com as respostas aos questionários Likert, obteve, em uma escala de 5, uma média de 1,7 (M= 1,7) com o desvio padrão, ou seja, a medida de dispersão das respostas em torno da 
média foi igual a 1,0 (DP=1,0). Já na segunda, percebemos que as escolas particulares têm uma média de uso de tecnologias de 3,6 (DP=1,0).

A Figura 1 demonstra um cenário que é reflexo do ensino público no Brasil. Há uma deficiência histórica quando se trata do uso de tecnologias nesse meio. Na declaração de Jomtien, documento fruto da conferência mundial sobre educação para todos, realizada em 1990 na Tailândia, as TIC foram apontadas como fatores que melhoram a qualidade e oferta da educação básica, bem como sua gestão.

Como mencionado no referencial teórico, o Brasil foi um dos 150 países que assinaram o documento se comprometendo com órgãos internacionais a implementar e ampliar o uso de tais recursos na educação. Uma das medidas tomadas em direção à implementação das TIC na educação no Brasil foi a criação em 1997 do PROINFO. Entretanto, como demonstrado de forma genérica no gráfico da Figura 1, nosso estudo aponta para uma direção diferente, sustentando o abismo existente entre a utilização das novas tecnologias nas esferas do ensino público e privado. $O$ dado demonstrado na Figura 1 reflete os apontamentos de Damasceno, Bonilla e Passos (2012, p. 33) e Silva (2014, p. 121; 185-192) acerca da precariedade dos equipamentos e infraestrutura para a implementação das novas TIC, bem como a falta de capacitação técnica dos professores para sua utilização, apesar da criação do PROINFO e PROUCA.

Observamos, ainda na Figura 1, uma discrepância significativa entre o uso das novas TIC na rede pública em relação às escolas particulares. Os alunos de rede pública muitas vezes nem sabem da existência do laboratório de informática em suas escolas e, quando esses indivíduos são levados até esses espaços, em geral o aproveitamento das potencialidades dos recursos lá disponíveis é mínimo e ineficiente, realidade esta também presente no contexto investigado por Silva e Medeiros (2014, p. 2) em escolas da rede pública da cidade de Campina Grande-PB.

Barreiras semelhantes foram apontadas na pesquisa de Carvalho (2012, p. 49-51), ao investigar em Londrina/PR o uso de tecnologias na educação pública, em especial o dos laboratórios de informática. A autora constatou a alegação de falta de tempo para participar dos cursos de capacitação para uso de tecnologias por parte dos docentes, que dizem que mesmo quando conseguem participar, se deparam com conteúdos extremamente tecnicistas nesses cursos, o que dificulta a assimilação dos conteúdos. Tal cenário contribui para a pouca utilização desses recursos por esses professores.

Dados como os apresentados na Figura 1 podem ser semelhantes aos resultados de estudos como o de Hashemi (2013, p. 58-59), que nos levam a entender que o problema do déficit de preparo técnico por parte dos docentes não é exclusividade do Brasil. Em sua análise, entre os motivos que levam os professores a utilizarem ou não as TIC o autor cita o déficit técnico como um dos principais problemas para a não utilização deses recursos.

Observamos na Figura 1 que, embora o desvio padrão seja significativo, o que pode ser explicado pela diversidade socioeconômica das escolas visitadas, levando-se então a respostas um pouco mais positivas em escolas situadas em zonas mais privilegiadas, ainda assim a diferença observada entre educação pública e particular nesse quesito avaliado é pertinente, similarmente ao que foi encontrado nos apontamentos de Barros e Araújo (2012, p. 5-9).

A partir do nosso estudo e das pesquisas aqui elencadas, entendemos que as 
razões para tal discrepância são absolutamente plausíveis. A falta de tempo dos professores para preparar aulas diversificadas com o suporte das tecnologias nos parece o motivo principal da falta de uso dessas ferramentas que, como já defendido, têm um potencial enorme, principalmente numa época em que os alunos estão inseridos de forma definitiva num mundo tecnológico. A falta de tempo também parece ser fator determinante na ausência de parte dos docentes nos cursos preparatórios, pois eles, em muitos casos, têm que trabalhar em dois turnos por não serem remunerados adequadamente, realidade esta que parece ser um fator central para explicar esta falta de tempo disponível.

Além disso, um fator que percebemos ser relevante é a concepção acerca das novas TIC assumida pelos alunos em relação à dos professores. Tal divergência pode estar relacionada à própria diferença de geração (idade) entre docentes e discentes. Essa diversidade de pensamentos está disposta na Figura 2 a seguir:

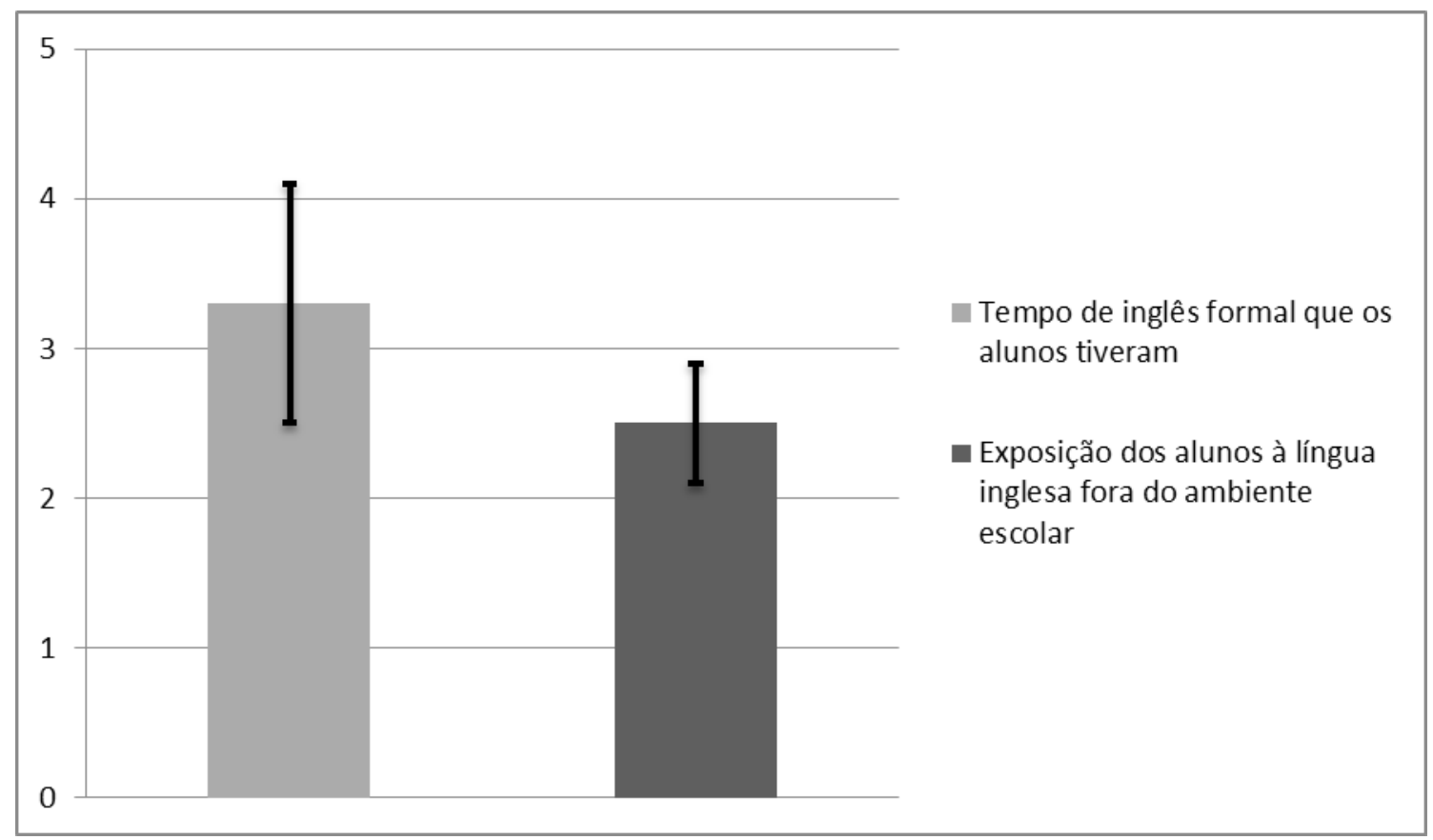

Figura 2: Estudo formal e sua influência extraclasse.

Fonte: os autores.

$\mathrm{Na}$ Figura 2, os dados da primeira coluna se referem ao tempo de estudo formal dos alunos entrevistados $(M=3,3, D P=0,8)$ em uma escala de 4 , já na segunda coluna está representada a exposição que esses mesmos alunos têm ao idioma inglês fora do ambiente escolar $(M=2,5, D P=0,4)$. A partir dos resultados apresentados, podemos depreender que os alunos têm uma média de tempo de estudo de inglês formal considerável, porém, a exposição a conteúdos no idioma-alvo ainda é tímida.

Uma explicação possível para a baixa exposição dos alunos à LI no extraclasse, mesmo com um tempo elevado de aprendizagem formal em suas respectivas escolas, pode estar associada aos indícios contundentes da ineficácia do ensino em suas escolas aferidos por meio do questionário que utilizamos para este artigo. Nesse sentido, autores como Lems (2016, p. 2-4) e Ghasemi e Hashemi (2011, p. 3099) têm igualmente apontado para o valor das novas TIC na construção de um ensino mais relevante, 
motivacional, eficaz e que faça com que os alunos sintam segurança para utilizar o que aprenderam fora do ambiente escolar também.

Entendemos que é papel do professor não somente preparar melhor os alunos para que possam continuar a aprendizagem autonomamente em casa, mas sugeri-los meios dos quais poderão se beneficiar em seu dia a dia fora da escola, uma vez que as novas TIC têm se mostrado de grande serventia para tal propósito. Contudo, percebemos que há uma falta de domínio dos próprios professores quanto ao uso das novas TIC, segundo mostram estudos como os de Silva (2014, p. 269-273), Carvalho (2012, p. 49-51) e Hashemi (2013, p. 58-59), algo que figura como um dos fatores que contribuem para a pouca ou nula utilização desses meios por parte dos docentes, como mostrou a Figura 1 no depoimento dos alunos.

As novas TIC têm o potencial de motivar e preparar os alunos para a utilização da língua-alvo em situações reais e os torna mais aptos e propícios a buscarem, fora do ambiente escolar, mais materiais que contribuam com seu aprendizado de forma cada vez mais original e relevante. Esse fato estabelece convergência com o que mostrou o estudo de Yang e Chen (2007, p. 250), uma vez que a exposição a conteúdos autênticos possibilitados pelas novas TIC aumenta o interesse dos alunos em buscarem mais exposição à língua fora do ambiente escolar.

Dados como dispostos na Figura 2 fazem-nos lançar a hipótese de que, havendo um aumento na utilização das novas TIC e que esta utilização seja feita principalmente com qualidade e de forma apropriada (o que passa, por entre outros fatores, pela qualificação dos professores), os dados da figura 2 poderiam se inverter, ou seja, os alunos com menos tempo de estudo formal já teriam maior facilidade e mais frequente aproveitamento dos recursos proporcionados pelas novas TIC fora do ambiente escolar.

Como já demonstramos, umas das possibilidades de se melhorar o uso da línguaalvo é o trabalho criterioso e didático com músicas. Hoje, existe uma infinidade de plataformas virtuais capazes de não só dar acesso a uma gama quase infinita de canções na língua-alvo, mas também propiciar materiais intrinsecamente didáticos, autênticos e motivantes com esse recurso. Com tais atributos, a música surge como uma possibilidade atrativa para a aprendizagem de $\mathrm{L} 2{ }^{10}$. Para entendermos essa relação, decidimos analisar a relação de alunos e professores com as músicas e verificar se elas têm sido utilizadas em sala de aula e como isso tem tomado forma. Para tanto, passaremos a considerar a Figura 3.

10 L2 significa segunda língua, ou seja, uma língua aprendida após a materna. 


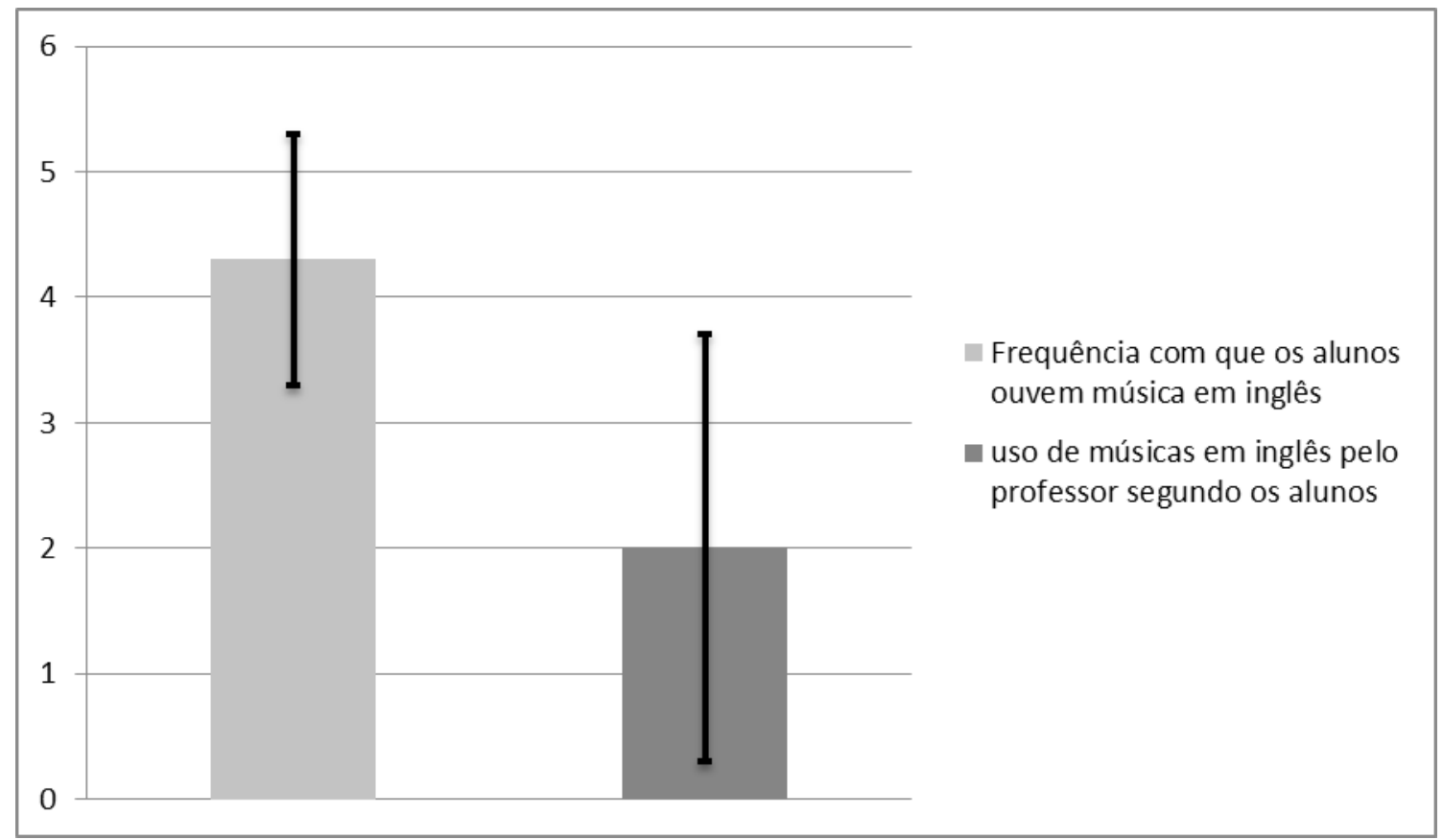

Figura 3: Exposição a músicas em inglês pelos alunos em casa e na escola. Fonte: os autores.

Na Figura 3, a primeira coluna demonstra a frequência com que os alunos ouvem músicas em inglês no dia a dia, tendo a média observada pelas respostas de 2,3 $(\mathrm{DP}=1,0)$. A coluna ao lado exibe os resultados do uso de músicas em inglês pelos professores segundo os alunos, com a média sendo de 2,0 (DP=1,7). Em ambos os casos, a escala vai até 5 .

Os benefícios da utilização da música na aquisição de uma língua é atestado por estudos como o de Yarmakeev et al (2016, p. 235-240). Como discutimos, Yousefi, Yekta e Farahmandian (2014, p. 2585-2586) demonstraram que, se o mesmo conteúdo é apresentado a dois grupos de aprendizes, aqueles que o recebem em forma de música obtêm maior sucesso na aquisição de vocabulário e em sua posterior retenção.

No entanto, a Figura 3 mostra que, pela ótica dos alunos, o trabalho didático com música é negligenciado por parte de professores como estratégia de ensino de LI, apesar do enorme interesse e da inserção dos alunos nesse meio mostrado pela primeira coluna. Tal cenário apresentado por nosso estudo contraria as aspirações de Israel (2013, p. 1364-1365), que propõe que os professores devem utilizar com maior frequência métodos que estejam mais de acordo com a realidade dos alunos, que ouvem música com muita frequência. Mesmo com o alto desvio padrão da segunda coluna $(1,7)$, devido à intensa variação nas respostas, ainda assim a diferença entre as duas colunas é notável.

Dois fatores que podem influenciar na diferença considerável entre as duas colunas da Figura 3 são que os alunos podem não considerar como aula de música aulas em que o professor acaba utilizando músicas de forma a desvalorizar o elemento lúdico desse tipo de mídia, abordando assim canções de forma extremamente gramaticista e desinteressante, ou quando os professores de fato não têm ou quase não têm utilizado esse recurso em sala de aula. Nesse último caso, essa realidade pode se dever a alguns fatores como, por exemplo, a falta de conhecimento teórico sobre como utilizar tal 
recurso, conforme Engh (2013, p. 113).

Lems (2016, p. 2-4) explica como as novas TIC têm transformado e potencializado a utilização de músicas no ensino de LI. A autora apresenta vários meios tecnológicos e atividades musicais concebidas a partir desses meios que, por serem lúdicas, proporcionam um ambiente de baixa ansiedade, autoconfiança e alta motivação, o que, segundo a hipótese do filtro afetivo de Krashen (2009, p. 30-32), é o melhor e mais favorável ambiente para a aprendizagem.

Entendemos que um aumento significativo na média da segunda coluna da Figura 3, aliado à correta utilização dos recursos auditivos como os aqui apontados, provocaria um aumento substancial na relevância da experiência de ensino e aprendizagem em sala de aula. Dados como esses fomentam a assunção de que o ambiente escolar brasileiro é, em geral, um espaço onde a ludicidade é subutilizada, exercícios e aulas como um todo são voltados apenas ao livro didático, há pouca motivação e muitos alunos acabam vendo tal ambiente como o oposto a uma atmosfera motivadora e prazerosa, fatores que contribuem então para desfavorecer a aprendizagem.

Além da música, outra possibilidade de aprendizagem de inglês, que pode ter efeitos extremamente positivos nos alunos, concentra-se na utilização de vídeos. Passaremos a analisar abaixo como esse recurso pode ser utilizado de forma relevante para os alunos e quais são seus benefícios.

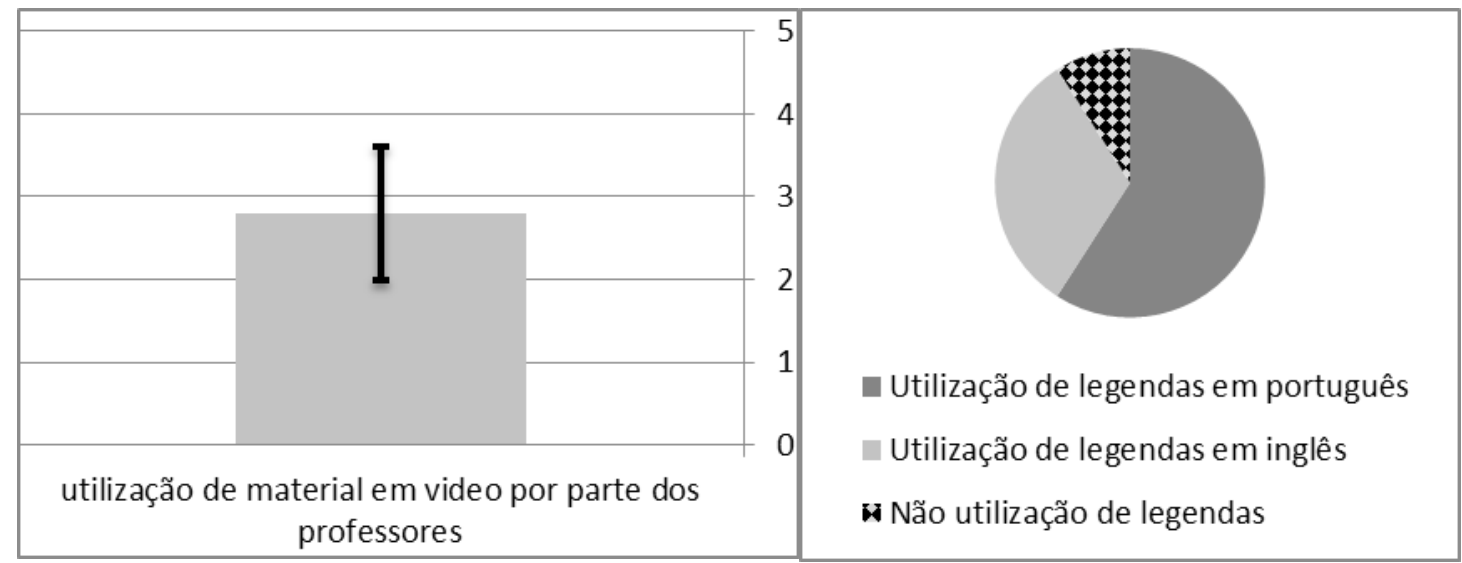

Figura 4: Uso de vídeo pelos docentes.

Figura 5: Uso de legendas.

Fonte: os autores.

A Figura 4 traz a frequência de utilização de materiais em vídeo por parte dos professores em sala de aula como estratégia pedagógica, com a média de 2,8 $(\mathrm{DP}=0,8)$ em uma escala que vai até 5 . Já a figura 5 mostra como se dá o uso desses materiais em vídeo. A parte cinza escura, que foi a maior, 59,9\%, representa o uso de materiais em vídeo com legendas em português por parte dos professores. A parte cinza clara, que é a de tamanho intermediário, representa o uso desses materiais em vídeo com legendas em inglês, com o percentual de 31,8\%. Por fim, a fatia menor se refere ao uso desses materiais sem legenda, com percentual de 9,0\%.

Esses dados dispostos nas Figuras 4 e 5 nos fazem retomar diversos estudos que demonstram os benefícios da utilização de vídeos no processo de ensino-aprendizagem de LI. Por meio de vídeos, os alunos podem ter exposição a materiais autênticos, ou seja, 
aqueles que não foram feitos com propósitos pedagógicos. Richards (2001, p. 252-253) apresenta vários estudos afirmando que materiais autênticos têm impacto positivo e direto na motivação dos alunos, pois se relacionam mais de perto com as necessidades dos aprendizes e contribuem para uma abordagem mais criativa pelos professores.

Os dados dispostos nas Figuras 4 e 5 dialogam com o que Krashen $(2009$, p. 7) propõe acerca de que as melhores formas de aprendizagem são aquelas que lançam mão de input compreensível e em situações de baixa ansiedade, contendo mensagens que os alunos realmente querem ouvir. Nesse sentido as legendas proporcionam tal cenário à medida que fazem mais compreensíveis materiais em vídeo, especialmente os que chamamos aqui de autênticos, que, em geral, são difíceis de serem assimilados pelos alunos. Os dados das figuras 4 e 5 apontam para uma escassez da utilização de materiais em vídeo, bem como uma maior utilização de legendas de iniciantes. Esse tipo de legenda, porém, é algo positivo para a aprendizagem.

Segundo as concepções de Markham e Peter (2003, p. 337-340), alunos que são expostos a legendas interlinguísticas obtêm uma melhor compreensão do conteúdo dos materiais do que os que são expostos ao mesmo material com legendas intralinguísticas. O estudo de Stewart e Pertusa (2004, p. 440-441), contudo, mostrou que as legendas intralinguísticas trazem melhor resultado no tocante à aquisição de vocabulário.

Como observamos na Figura 4 acima, a utilização de vídeos em sala de aula ainda é insuficiente por parte dos professores, quando deveria ser maior devido à grande contribuição que esse recurso pode proporcionar a uma aula de LI. Vemos também na Figura 5 que o tipo de legendas que os professores mais utilizam é a interlinguística, de bom auxílio para o aprendizado. Porém, segundo postulam Markham, Peter e McCarthy (2001, p. 444) e Markham e Peter (2003, 339-340), as legendas interlinguísticas deveriam ser utilizadas nos níveis mais iniciais da aprendizagem da língua, e depois, conforme os estudantes vão progredindo em seu uso da língua-alvo, deve haver uma progressão para o uso de legendas intralinguísticas e em um próximo estágio para o de vídeos sem legendas. Os docentes, considerando que todos os alunos da pesquisa são do ensino médio e já têm um tempo elevado de aprendizagem de LI formalmente, segundo a Figura 2, já deveriam estar utilizando menos esses materiais com legenda em português e mais com legendas em inglês e até sem legendas.

Entendemos que a insuficiência do uso de vídeos em sala de aula pelos professores e a forma como eles utilizam as legendas é mais um componente no conjunto de fatores que podem estar apontando para a ineficiência do sistema educacional brasileiro com relação ao ensino de LI.

\section{Considerações finais}

O objetivo geral desta pesquisa consistiu em identificar quais são as implicações docentes e discentes na utilização das novas TIC no processo de ensino-aprendizagem de LI. Considerando tal meta, conseguimos estabelecer dois cenários. O primeiro, com uma conotação mais pessimista, revela a falta de utilização pelos professores de vídeos, música e outros recursos providos pelas novas TIC. O segundo cenário, mais otimista, revela uma gama de possibilidades de se trabalhar com as novas tecnologias devido ao perfil dos alunos. Eles estão bem inseridos nas novas TIC, gostam de vídeos, assistem 
séries, ouvem música com bastante frequência, jogam. Temos um campo promissor (o cenário dos alunos inseridos nas possibilidades das novas TIC) para se plantar (lançar mão desses recursos nas aulas) e esperar por uma boa colheita (bons resultados, melhor aprendizagem).

Em relação ao objetivo de identificar como se dá o uso de tecnologias pelos professores dentro de escolas públicas em oposição às particulares, notamos que há uma diferença evidente em sua utilização nesses dois contextos. As escolas da rede particular utilizam mais tais tecnologias em comparação às da rede pública, além de contarem também com uma estrutura física superior à das escolas particulares e melhor preparo dos profissionais do ensino, fruto dos investimentos de que são alvos essas instituições. Dessa forma, nossos dados refletem a estrutura macrossocial e confirmam a deterioração do sistema público de ensino em sua esfera infraestrutural.

Além disso, observamos que, no que se refere ao objetivo de identificar o tempo de aprendizagem formal de LI e a exposição que os discentes têm ao idioma fora do ambiente escolar, o tempo de aprendizagem formal dos discentes em LI é considerável, porém, não há um resultado elevado quanto à exposição que têm ao idioma-alvo fora da escola. Conectamos esse fato à qualidade do ensino que têm recebido na escola. As novas TIC são vistas como canais que possibilitam uma aprendizagem mais substancial, integrativa e relevante, o que refletiria, caso fossem utilizadas de forma contínua, apropriada e em uma maior e mais qualificada exposição ao idioma dentro e fora do ambiente escolar.

Sobre a meta de apontar a frequência com que os discentes ouvem músicas em inglês e a utilização dessa abordagem por parte dos docentes segundo os alunos, verificamos que os alunos estão, em sua maioria, imersos no mundo da música em LI, embora esses recursos sejam pouco utilizados em suas escolas. Consideramos que fatores que podem levar a essa realidade são a falta de conhecimento teórico dos professores sobre como se beneficiar de tal recurso e o fato de que, quando eles o utilizam, fazem-no de maneira tão gramaticista que os alunos perdem a referência de que estão tendo uma aula de música. O conhecimento teórico apropriado a respeito das potencialidades das novas TIC no ensino de música em sala pode assim mudar esse quadro.

Tendo em vista o objetivo de descrever como é feita a utilização de vídeos em inglês pelos docentes, a forma como essa prática se dá e se os utilizam com legendas em língua portuguesa, inglesa ou sem legendas, chegamos à conclusão de que os professores utilizam pouco esse recurso em sala de aula, o que consiste em perda para o processo, pois material audiovisual é um aliado potente em ensino-aprendizagem de línguas. Além disso, quando utilizam esse tipo de material, fazem-no mais com legendas em português, o que, segundo os teóricos consultados, pode denunciar a ineficiência do sistema educacional brasileiro, já que, após o período grande que os alunos tiveram de exposição formal ao idioma, já se esperaria que estivessem aptos a acompanhar esse tipo de material com legendas em inglês.

A análise de todos os resultados encontrados nos levou a entender que há um déficit em relação ao ensino de LI nas escolas-alvo desta pesquisa quanto ao uso das novas tecnologias, mas descobrimos também que esses meios de aprendizagem podem trazer mudanças extremamente positivas para a prática escolar.

Ao realizarmos esta investigação, fomos capazes de entender melhor as diversas 
nuances ligadas à utilização das novas TIC no processo de ensino-aprendizagem de LI. O cenário ainda não é o ideal, pois observamos uma prática escolar aquém daquela em que a aprendizagem floresce, aproveitando assim todo o potencial de que temos hoje à nossa disposição. Todavia, à medida que os professores começarem a utilizar e se inserir mais no mundo das novas TIC, descobrindo o potencial que essas ferramentas têm para revolucionar o processo educativo brasileiro, há esperança de que o Brasil recupere o tempo perdido no processo histórico de aprendizagem de LI.

\section{Referências}

BARROS, C. M; ARAÚJO, G. R. Novas tecnologias: Escola pública versus escola particular. In: FIPED - Fórum Internacional de Pedagogia, 4., 2012, Parnaíba. Anais eletrônicos... Campina Grande: Realize, 2012. Disponível em: $<$ http://www.editorarealize.com.br/revistas/fiped/resumo.php?idtrabalho=443>. Acesso em: 27 jan. 2018.

BRASIL. Base nacional comum curricular: Ensino médio. 2017. Brasília: MEC, 2017. Disponível em: <http://basenacionalcomum.mec.gov.br/wpcontent/uploads/2018/04/BNCC_EnsinoMedio_embaixa_site.pdf >. Acesso em: 27 mai. 2018.

BRASIL. Decreto n 6.300, 12 de dezembro de 2007. Dispõe sobre o PROINFO. Diário Oficial da União, poder Executivo, Brasília, DF, 12 dez. 2007. Seção 1, p. 3. Disponível em: <http://www.planalto.gov.br/ccivil_03/_ato2007-2010/2007/decreto/d6300.htm>. Acesso em: 27 jan. 2018.

BRASIL. Parâmetros curriculares nacionais: Ensino médio. 2000. Brasília: MEC, 2000. Disponível em: <http://portal.mec.gov.br/programa-saude-da-escola/195-secretarias112877938/seb-educacao-basica-2007048997/12598-publicacoes-sp-26500221>. Acesso em: 27 jan. 2018.

CARVALHO, J. M. O uso pedagógico dos laboratórios de informática nas escolas de Ensino Médio de Londrina. 2012. 57 f. Trabalho de Conclusão de Curso (Graduação em Pedagogia) - Universidade Estadual de Londrina, Londrina, 2012.

DAMASCENO, H. L. C.; BONILLA, M. H. S.; PASSOS, M. S. C. Inclusão digital no Proinfo Integrado: perspectivas de uma política governamental. Inclusão Social, Brasília, v. 5, n. 2, p. 32-42, 2012. Disponível em: <http://revista.ibict.br/inclusao/article/viewFile/1675/1881>. Acesso em: 27 jan. 2018.

ENGH, D. Why Use Music in English Language Learning? A Survey of the Literature. English Language Teaching, Toronto, v. 6, n. 2, p. 113-127, 2013. Disponível em: <http://www.ccsenet.org/journal/index.php/elt/article/view/23819/15117>. Acesso em: 27 jan. 2018.

GHASEMI, B.; HASHEMI, M. ICT: Newwave in English language learning/teaching. 
Procedia Social and Behavioral Sciences. Istanbul, v. 15, p. 3098-3102, 2011. Disponível em: <https://www.sciencedirect.com/science/article/pii/S1877042811007981>. Acesso em: 27 jan. 2018.

GRIM, B. J.; HARMON, A. H.; GROMIS, J. C. Focused Group Interviews as an Innovative Quanti-Qualitative Methodology (QQM): Integrating Quantitative Elements into a Qualitative Methodology. The Qualitative Report, [S.I.], v. 11, n. 3, p. 516-537, 2006. Disponível em: <http://www.nova.edu/ssss/QR/QR11-3/grim.pdf>. Acesso em: 27 jan. 2018.

HASHEMI, B. The investigation of factors affecting the adoption of ICTs among English language teachers in ESL context. International Journal of Language Learning and Applied LinguisTIC World, [S.I.], v. 4, n. 1, p. 55-70, 2013. Disponível em: $<$ http://ijllalw.org/September2013fullissue.pdf>. Acesso em: 27 jan. 2018.

HUANG, H; ESKEY, D. E. The effects of closed-captioned television on the listening comprehension of intermediate English as a second language (ESL) students. $J$. Educational Technology Systems, [S.I.], v. 28, n. 1, p. 75-96, 1999. Disponível em: <http://journals.sagepub.com/doi/pdf/10.2190/RG06-LYWB-216Y-R27G>. Acesso em: 27 jan. 2018.

HULME, A. Kukulska; SHIELD, L. An overview of mobile assisted language learning: From content delivery to supported. ReCALL, [S.I.], v. 20, n. 3, p. 271-289, 2008. Disponível em: $\quad<$ https://www.cambridge.org/core/journals/recall/article/an-overview-of-mobileassisted-language-learning-from-content-delivery-to-supported-collaboration-andinteraction/55FE8FC0F278B5A2E55A8501F059F14C>. Acesso em: 27 jan. 2018.

ISRAEL, H. F. Language learning enhanced by music and song. LICEJ - Literacy information and computer education journal, [S.L.], v. 2, n. 1, p. 1360-1366, 2013. Disponível em: <http://infonomics-society.org/wp-content/uploads/licej/publishedpapers/special-issue-volume-2-2013/Language-Learning-Enhanced-by-Music-andSong.pdf>. Acesso em: 27 jan. 2018.

JARVIE, H.; ACHILLEOS, M. From Computer Assisted Language Learning (CALL) to Mobile Assisted Language Use (MALU). TESL - EJ, Teaching English as a Second or Foreign Language. [S.I.], v. 16, n. 4, p. 1-18, 2013. Disponível em: <http://www.teslej.org/pdf/ej64/a2.pdf>. Acesso em: 27 jan. 2018.

KOKSAL, D. To kill the blackboard? Technology in language teaching and learning. TOJET - The Turkish Online Journal of Education Technology, [S.I.], v. 3, n. 3, p. 62-72, 2004. Disponível em: <http://www.tojet.net/articles/v3i3/339.pdf>. Acesso em: 16 fev. 2018.

KRASHEN, S. D. Principles and Practice in Second Language Acquisition. 1. internet edition. [S.I.: $2009 . \quad$ S.n.], Disponível em: <http://www.sdkrashen.com/content/books/principles_and_practice.pdf >. Acesso em: 27 jan. 2018. 
LEMS, K. Learning English Through Music in the Digital Age. TESOL Video News online newsletter of the TESOL International Association. Chicago, n. 10, p. 5, 2016. Disponível em: $\quad<$ http://newsmanager.commpartners.com/tesolvdmis/issues/2016-07-26/4.html>. Acesso em: 27 jan. 2018.

LINDAMAN, L.; NOLAN, D. Mobile-Assisted Language Learning: Application development projects within reach for language teachers. The IALLT Journal, [S.I], v. 45, n. 1, p. 1-22, 2015. Disponível em: <http://ialltjournal.org/index.php/ialltjournal/article/view/64/55>. Acesso em: 27 jan. 2018.

MARKHAM, P. L.; PETER, L.; MCCARTHY, T. The effects of native language vs. target language captions on foreign language students' DVD video comprehension. Foreign Language Annals, [S.I.], v. 34, n. 5, p. 439-445, 2001. Disponível em: <http://onlinelibrary.wiley.com/doi/10.1111/j.1944-9720.2001.tb02083.x/full>. Acesso em: 27 jan. 2018.

MARKHAM, P. L.; PETER, L. The influence of English language and Spanish language captions on foreign language listening/reading comprehension. Journal of Educational Technology Systems, [S.I.], v. 31, n. 3, p. 331-341, 2003. Disponível em: <http://journals.sagepub.com/doi/pdf/10.2190/BHUH-420B-FE23-ALA0>. Acesso em: 27 jan. 2018.

MCLOUGHLIN, C; LEE, M. J. W. Social software and participatory learning: Pedagogical choices with technology affordances in the Web 2.0 era. In: ASCILITE, 16., 2007, Singapura. Anais eletrônicos... Singapura: [s.n.], 2007. p. 664-675. Disponível em: <http://www.ascilite.org/conferences/singapore07/procs/mcloughlin.pdf>. Acesso em: 06 mar. 2018.

MERRIAM, A. P. The anthropology of music. 1. ed. Evanston: Northwestern University Press, 1964. 358 p.

NEUMAN, S. B.; KOSKINEN, P. Captioned Television as Comprehensible Input: Effects of Incidental Word Learning from Context for Language Minority Students. Reading research quarterly, [S.I.], v. 27, n. 1, p. 94-106, 1992. Disponível em: $<$ https://www.jstor.org/stable/747835?seq=1\#page_scan tab_contents $>$. Acesso em: 27 jan. 2018.

PRODANOV, C. C.; FREITAS, E. C.. Metodologia do trabalho científico [recurso eletrônico]: métodos e técnicas da pesquisa e do trabalho acadêmico. 2. ed. Novo Hamburgo: Feevale, 2013. Disponível em: <http://www.feevale.br/Comum/midias/8807f05a-14d0-4d5b-b1ad-1538f3aef538/E-book \%20Metodologia\%20do\%20Trabalho\%20Cientifico.pdf>. Acesso em: 27 jan. 2018.

RICHARDS, J. C. Curriculum Development in Language Teaching. 1. ed. Cambridge: Cambridge University Press, 2001. 321 p.

SILVA, J. S. Os desafios de navegar: a colaboração como bússola da formação contínua 
de professores de língua inglesa mediante as novas TIC 2011. 209 f. Dissertação (Mestrado em Letras e Linguística) - Universidade Federal de Goiás, Goiânia, 2011.

SILVA, A. P. P. Formação continuada de professores para o Projeto UCA: análise dos processos formativos prescritos, vivenciados e narrados. 2014. 335 p. Tese de doutorado (Programa de Pós Graduação em Educação) - Universidade Federal do Rio Grande do Sul, Porto Alegre, 2014.

SILVA, A.; MEDEIROS, D. C. A. Laboratórios de Informática Nas Escolas: que espaço é esse?. Compartilhando saberes, [S.I.], n. 1, p. 21-37, 2014. Disponível em: <http://www.sec.pb.gov.br/revista/index.php/compartilhandosaberes/article/view/7/4>. Acesso em: 27 jan. 2018.

STEWART, M. A.; PERTUSA, I. Gains to language learners from viewing targetlanguage closed-captioned films. In: FOREIGN LANGUAGE ANNALS, 2004, [S.I.]. Anais eletrônicos... [S.I.: S.n.], 2004. p. 438-447. Disponível em: <http://onlinelibrary.wiley.com/doi/10.1111/j.1944-9720.2004.tb02701.x/full\#references>. Acesso em: 27 jan. 2018.

UNESCO. Declaração de Jomtien. 1990. Conferência mundial sobre educação para todos. Disponível em: <http://unesdoc.unesco.org/images/0008/000862/086291por.pdf>. Acesso em: 27 jan. 2018.

VANDERPLANK, R. The value of teletext subtitles in language learning. ELT Journal, [S.I.], v. 42, n. 4, p. 42-4, 1988. Disponível em: <https://academic.oup.com/eltj/articleabstract/42/4/272/484447>. Acesso em: 27 jan. 2018.

WARSCHAUER, M. Computer-assisted language learning: An introduction. In: FOTOS, S. (Ed.). Multimedia language teaching. Tokyo: Logos international, 1996. p. 3-20.

WARSCHAUER, M.; HEALEY, D. Computers and language learning: An overview. Language Teaching, [S.I.], v. 31, n. 2, p. 57-71, 1998. Disponível em: $<$ https://www.cambridge.org/core/journals/language-teaching/article/computers-andlanguage-learning-an-overview/0CF20A4837B377B3A214BF410F4775EB >. Acesso em: 27 jan. 2018.

WATSON, D. M. Pedagogy before technology: rethinking the relationship between ICT and teaching. Education and information technologies, Netherlands, v. 6, n. 4, p. 251-266, 2001. Disponível em: <http://citeseerx.ist.psu.edu/viewdoc/download?

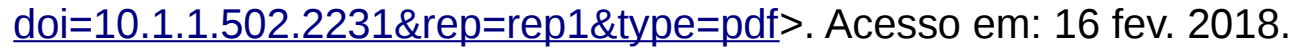

YANG, S. C.; SHEN, Y. J. Technology-enhanced language learning: A case study. Computers in human behavior, [S.I.], v. 23, n. 1, p. 860-879, 2007. Disponível em: <https://www.sciencedirect.com/science/article/pii/S0747563206000288>. Acesso em: 27 jan. 2018. 
YARMAKEEV, I. E. et al. Folk songs do magic in teaching speech and grammar patterns in EFL class. Journal of Language and Literature, [S.I.], v. 7, n. 1, p. 235-240, 2016. Disponível

em:

$<$ https://www.researchgate.net/publication/311605672_Folk_songs do magic in teaching speech_and_grammar_patterns_in_EFL_class>. Acesso em: 27 jan. 2018.

YOUSEFI, A.; YEKTA, R. R.; FARAHMANDIAN, H.. The Effect of Modern Lyrical Music on Second Language Vocabulary Acquisition. Mediterranean Journal of Social Sciences, Roma, v. 5, n. 23, p. 2584-2586, 2014. Disponível em: <http://www.mcser.org/journal/index.php/mjss/article/view/4903/4745>. Acesso em: 27 jan. 2018.

Recebido em dia 02 de junho de 2018. Aprovado em dia 19 de julho de 2018. 